\title{
Using Quality Concepts to Improve Reference Services
}

\section{Janet Dagenais Brown}

Much has been written about how reference librarians can evaluate and improve the quality of the answers they provide to reference questions. There has been considerably less discussion, however, about how to improve the quality of the delivery of those answers. Suggestions for improving the quality of service found in the business literature are applicable to improving reference service as well. Insights gained from a review of the quality literature were used by the Wichita State University Library to improve the quality of reference service offered. Descriptions of a number of projects undertaken by the Reference Department as an outgrowth of the business literature studies are included.

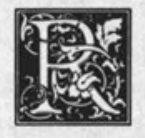

eference librarians have become increasingly concerned about the quality of the reference service they provide. We know that having positive and productive experiences in the library will encourage students to use it frequently to enhance and augment their formal course work. One way libraries can cultivate "repeat business" from students is to provide them with high-quality reference service.

Recently, realizing that it had been some time since a thorough evaluation of their service had been made, reference librarians at the Wichita State University Library decided to see what they could do to improve the quality of their reference service. It was not difficult to find information describing the characteristics of high-quality reference service. From the national level to the local level, librarians have struggled to define and measure good reference service. The Standards and Guidelines Committee of the Reference and Adult Services Division of the American Library Associa- tion, for example, has developed "Information Services for Information Consumers: Guidelines for Providers," which outlines in detail what libraries must do to provide quality service to their patrons. It states, "The library should provide users with complete, accurate answers to their information queries regardless of the complexity of those queries," and stresses that "Information service staff members must communicate easily and effectively with the full range of the library's clientele regardless of a client's age, gender, ethnicity, disability, sexual preference, or Englishlanguage proficiency."1

On a smaller scale, individual librarians have also tried to define the characteristics of good reference service for their particular types of libraries. James Shedlock, in an article entitled "Defining the Quality of Medical Reference Service," states that "quality reference service depends on three critical elements: the answer, the process, and the delivery." According to Shedlock, the answers supplied by "quality reference

Janet Dagenais Brown was Reference Specialist at the Wichita State University Library, Wichita, Kansas 67260-0068 at the time this paper was written. She has recently been appointed to the newly created Undergraduate Services Librarian position at the WSU Library. 
service must provide accurate, correct, and truthful information." The process or "way in which information is found on behalf of the user" must be efficient and timely. And the delivery or "style in which an answer is communicated to a user .... strongly influences the perception of quality." He goes on to say, "Sometimes how information is delivered is more important than what is delivered."2

From the national level to the local level, librarians have struggled to define and measure good reference service.

Both the guidelines from the ALA and the philosophy of an individual librarian emphasize that high-quality Reference Service is made up of two parts. The first is a complete, accurate, and timely answer (the "what"), and the second is a delivery process that is responsive to the individuality of each patron (the "how").

\section{THE PROBLEM}

While guidelines and definitions that describe quality reference service are helpful and stimulating to information providers, they do not really offer practical direction. In the library literature, there has been much evaluation of, and debate about, the accuracy of the answers reference librarians provide patrons. However, few articles or books offer actual step-by-step methods for improving reference service delivery. It seems to be much more difficult to measure how a service is perceived by its users than to determine whether a question is answered correctly.

\section{THE LITERATURE ON QUALITY}

Fortunately, librarians are not the only professionals trying to define and provide quality service. Our colleagues in the fields of business and organizational management have published reams of information in books and journals on "Quality Service," "Service Excellence," and "Customer Satisfaction." Are there techniques that these professions have developed that librarians might apply to making our own service "excellent"?

A review of the recent business literature led to over seventy appropriate books and articles on quality service published for the most part between 1990 and 1992. Three names appeared over and over in the quality literature. This "quality triumvirate" includes W. Edwards Deming, Joseph M. Juran, and Philip B. Crosby. Each offers important ideas about methods for improving service that would be of interest to reference librarians.

\section{Deming}

The name W. Edwards Deming is almost synonymous with the acronym TQM (Total Quality Management), which, according to an article in Nation's Business, "has become the most popular abbreviation since TGIF." ${ }^{3}$ Deming's "14 Points for Management" state that, in order for quality to occur in an organization, managers must create a constancy of purpose for the organization as a whole, initiate training and retraining for employees, provide leadership, break down barriers between departments, eliminate employee fear of reprisals, and seek constant improvement for the organization. ${ }^{4} \mathrm{~A}$ recent article in $\mathrm{Li}$ brary Journal by Terry and Kitty Mackey, "Think Quality! The Deming Approach Does Work in Libraries," explains how Deming's fourteen points can be adapted to libraries. ${ }^{5}$

\section{Juran}

Joseph M. Juran, another quality expert, developed the "Quality Trilogy" as a guide to quality for managers. It includes steps for Quality Planning, Quality Control, and Quality Improvement. ${ }^{6}$ Quality Planning focuses on identifying the organization's customers, and then defining their needs. Quality Control assists the workers by providing feedback on performance, and Quality Improvement refers to the process of continually striving to prevent problems in quality rather than dealing with them only after 
they have occurred. Juran's massive Quality Control Handbook includes a useful chapter on providing quality in the "Service Industries."7

\section{Crosby}

Philip B. Crosby, like Deming, has developed a fourteen-point "Quality Improvement Process" for managers. He also stresses that management must make a commitment to quality improvement, and that it must be an ongoing process; training on quality must be provided for employees; and "zero defects" should be the company's performance standard. Problems should be prevented rather than corrected later. ${ }^{8}$

Common threads run through the philosophies of these three men, and indeed through all of the available articles and books about providing quality service. The "Quality Creed" set forth in these works could be said to include four major parts:

- The top management of the organization must make a commitment to quality improvement.

- Employees must be engaged in the improvement process through involvement and empowerment.

- The organization must work continuously at improving quality.

- The organization must be customerdriven - it should identify its customers and strive to meet their needs.

\section{CUSTOMERS AND CUSTOMER SERVICE}

While most reference librarians may not have a major impact on setting the management style of the library, there are parts of this creed on which they can take action. Reference departments can make their reference service more "customer driven" and involve all reference librarians in the process. They should focus their efforts on the "how" of service delivery.

It is useful to understand more about the service interaction and what it is that makes "buying" and evaluating a service (such as reference service) different for the customer than "buying" and evaluating a material product. According to Rich- ard Normann in Service Management: Strategy and Leadership in Service Businesses, The person buying a product, such as a car or a pen, may concentrate his evaluation process on the product itself. It is there, it is tangible, and it can be tested and investigated from every angle.... The customer who wants to buy a service is in a different position. The service is not yet there to be experienced-it cannot be demonstrated without being sold.'

Also, a product, such as a personal computer, can be produced without the consumer ever coming in contact with the people who manufacture it. This is not true with services. Not only will consumers have to come in direct contact with the person providing the service but they also will have to be actively involved in the actual production of the service. It is a joint effort, and it is highly personal. In his book Normann points out that "It is the skill, the motivation and the tools employed by the firm's representative and the expectations and behaviour of the client which together will create the service delivery process." ${ }^{10}$

What the consumer experiences during this contact with the service provider has been called the "Moment of Truth," a phrase coined by Swedish airline magnate Jan Carlzon. A moment of truth is "that precise instant when the customer comes into contact with any aspect of your business and, on the basis of that contact, forms an opinion about the quality of your service and, potentially, the quality of your product."11

Reference librarians will encounter many of these moments of truth during each shift at the Reference Desk. How well these moments are managed will determine how satisfied our customers are with our service. It is important to remember that our service must have some kind of value for our patrons. They are not getting it for free, even though no money changes hands. Patrons spend time, money, energy and effort when using our service. At the same time, they may experience inconvenience and frustration. $^{12}$ Therefore, each moment of truth must be managed or performed 
carefully because "customers judge service by the quality of their interactions with the people who provide it. The more contact employees have with customers, the more critical employee behavior is to perceptions of service quality." ${ }^{\prime 13}$

What happens if reference librarians don't manage moments of truth well? Patrons will miss out on more than just good answers to their questions and a good feeling about libraries. Reference librarians have goals for their interactions with customers that go beyond just making them happy. In academic libraries, especially, we want the library to become an integral part of the educational process for all students. We want to reach them and teach them how to become independent learners in the library.

\section{EFFORTS TO EVALUATE THE "SERVICE ENCOUNTER"}

Reference librarians at the Wichita State University Library wondered how we were doing with moments of truth at our Reference Desk. Could we apply some of the same principles of quality service used by businesses to our own service function? We decided that the first step to improving our service quality was to find out more about our "customers" - exactly who were our patrons, and were we meeting their library needs?

In the fall of 1990 we embarked upon several projects designed to answer these questions. Perhaps it would be useful to others to hear about the ideas we tried and experiences we had. Our approach involved four projects: (1) a Problem Log; (2) a Suggestion Box; (3) the Wisconsin-Ohio Reference Evaluation Program; and (4) a Reference Automation Quality Circle.

\section{Problem Log}

What We Did: A "Reference Area Problem Log" was developed for the Reference Desk. Problems or complaints received at the Reference Desk from students, faculty, or staff (including other library employees and ourselves) regarding the use of materials, equipment, and services in the Reference Area were documented on this form. Columns were set up to record the date, time, and nature of the complaint, as well as the solution offered the patron by the librarian.

What We Learned: The Problem Log pointed out several distinct categories of user problems and/or needs in the Reference Area:

- The wide variety of computer equipment available, associated with frequent technical problems, was a major source of frustration for both patrons and staff.

- The constant moving of CD-ROM workstations as new databases were added was frustrating to users, and indicated a need for better signage in the Reference Area.

- Patrons would have liked more oneon-one instruction from a librarian on how to use the computer systems available.

- The growing number of databases available in the library was creating a need for additional instructional handouts.

Reference librarians have goals for their interactions with customers which go beyond just making them happy.

In addition to the insights gained about problems patrons were having in the Reference Area, the Problem Log provided a number of unanticipated benefits. Since it was completely nonconfrontational, it opened up another avenue for communicating among ourselves about problems. It also provided a good way for the librarians to do some immediate "venting" about frustrating encounters with patrons.

\section{Suggestion Box}

What We Did: The library had not had a Suggestion Box in place for years, and it seemed an effective way to solicit feedback about our services. A form was designed to accommodate suggestions, comments, and requests for books.

A box for collecting suggestions and a bulletin board for posting responses 
were mounted on a wall just outside the Reference Area. Within days, suggestions began appearing in the box. Suggestions were routed to the department best able to respond, and responses were then posted on the bulletin board for two weeks.

What We Learned: Over sixty suggestions were received during the first year. Comments fell into several categories:

- The majority referred to the library building and facilities - the usual requests for a lounge or vending machine area, more telephones, etc.

- A few concerned library policies"Why is it that materials may only be renewed twice?"

- Several described problems using library finding tools, and gave us the opportunity to explain, or offer additional help by appointment.

- One or two offered suggestions for ways to make things easier for patronsfor example, "Put blocks in the stacks to indicate when there is a second copy of a periodical on microfilm."

These suggestions have been invaluable in making us more aware of patron needs and the problems they are having in the library. The Suggestion Board has provided each "suggester" with a personal reply, and the anonymous nature of the exchange allows patrons to feel safe about communicating their ideas and frustrations. The Suggestion Box has proven useful in soliciting feedback, and anyone who stops to read the responses has the opportunity to learn something about the library.

\section{Wisconsin-Ohio Reference Evaluation Program}

What We Did: An effort was made to identify a survey instrument that would allow us to evaluate not only how well we were answering reference questions, but provide more information about (1) the characteristics of our customers, (2) how well we were meeting their needs, and (3) areas where we might need to improve our service to them. We hoped to find an instrument that would give us an awareness of how librarians, as well as patrons, were perceiving each "moment of truth" at the Reference Desk.
A review of the literature turned up many studies on methods of evaluating reference service. "Unobtrusive" surveys were quickly eliminated because of their rather negative "spylike" approach to evaluation. Their use of "canned" reference questions which had definite right and wrong answers seemed to oversimplify the reference transaction. Many questions have more than one "appropriate" answer, depending on the needs, skill, and knowledge of the questioner. An unobtrusive test would not point out our skills (or lack of them) on nonfactual questions, which frequently require lengthy question negotiation. The more open-ended questions are just as common, and are usually much more difficult to answer than factual questions. An unobtrusive test would focus on the "what" (the answer) of our reference service rather than on the "how" (the delivery).

Eventually, an "obtrusive" survey instrument was located which allowed both patrons and librarians to participate in the evaluation. The WisconsinOhio Reference Evaluation Program instrument (called the Reference Transaction Assessment Instrument or RTAI), developed by Charles Bunge and Marjorie Murfin not only provides libraries with information about question-answering success (i.e., "customer satisfaction") but also furnishes data on patron characteristics, subject areas and level of difficulty of patrons' questions, amount of time spent by the librarian in answering the questions, number of sources consulted, level of busyness at the desk at the time of the question, etc.

The Wisconsin-Ohio Reference Evaluation Program allows each participating library to compare its survey results with those of:

- all academic libraries in its same size category (based on total number of volumes in library)

- the top-scoring library in that size category

- all academic libraries in the sample ${ }^{14}$ Validity of the Survey. In an article for $R Q$ in 1985, Charles Bunge reported on the development of the Reference 
Transaction Assessment Instrument and its later test in fifteen academic libraries. ${ }^{15}$ According to the article, the instrument showed an initial "high face validity" among reference librarians asked to comment on the form. Two years later, in College \& Research Libraries, Marjorie Murfin and Gary Gugelchuk described the rigorous series of reliability measures, such as Cronbach's alpha, and validity tests to which the instrument had subsequently been subjected. ${ }^{16}$ By the time our library administered the survey five years later, sixty-seven other academic libraries had already participated in this evaluation program, indicating its acceptance as a significant and validated instrument.

Administration of the Survey. The Wisconsin-Ohio Reference Evaluation Program allows libraries to choose the number of computer-scannable survey forms they wish to give out-100, 150 , or 200 . We chose the 200 form category, and thus administered 200 questionnaires for reference questions we received, and 200 shorter forms for directional questions. We selected a typically busy week at the end of March during the spring semester of 1992 to administer the survey. Thirteen reference librarians and one paraprofessional participated. We selected four to five hours each weekday to conduct the survey. Different hours were selected each day and evening in an effort to get an accurate picture of our patrons.

Twenty questionnaires were passed out each hour-one to each of the first ten patrons asking directional questions, and one to each of the first ten patrons asking reference questions. Each of the two reference librarians on duty was responsible for five directional question forms and five reference question forms. Our Reference Desk was extremely busy, and we thought that this number of questionnaires would be the maximum "do-able" amount in an hour. When the librarians had given out all ten of their forms, they were finished with the survey for that hour.

After answering a question, the reference librarian would ask the patrons if they would be willing to participate in a survey that would help us evaluate our reference service. Most patrons were very willing to help. Librarians separated the forms, handed back the patron's copy, and indicated a basket near the desk for completed forms. Librarians then made notes to themselves about the question on the corresponding part of the form, and completed each one later when off the desk. Since the patrons' and librarians' forms had corresponding numbers on them, interested librarians could go back, match up their forms with patrons' forms, and see how they had performed individually.

Limitations of the Survey. Although our intent was to get a broad and random selection of responses to the survey, a number of factors may have affected the results of our survey: we did not administer the survey on weekends, and may have missed some of our "nontraditional" students who tend to use the library more frequently on those days; only "walk-in", as opposed to phone, patrons were surveyed; and, some of our frequent users participated in the survey several times, thus limiting the total number of unique responders exposed to the survey. Most likely, none of these factors had a major impact on the survey results. However, the survey itself may have one limitation. Bunge and Murfin have cautioned that libraries participating in this program are self-selected. Since they are not a random sample, they may not be representative Reference Departments, although there is no evidence to suggest that they are not. ${ }^{17}$

What We Learned: Of the sixty-seven academic libraries that had already participated in this program, twenty-two were in our same size category-medium-sized libraries holding 500,000999,999 volumes. The survey results allowed us to compare our library's performance with the averaged scores of these other twenty-two academic libraries, as well as with the averaged scores of all sixty-seven participating academic libraries.

Especially interesting was the data that allowed us to compare our scores 
with those of the academic library which had received the highest score on patron satisfaction. Patron satisfaction was based on the patrons answering that they had found exactly what was wanted and were completely satisfied.

In addition to providing valuable insights into our reference service, the survey results confirmed what we already knew-because our desk was so busy, we were unable to give patrons as much assistance as they felt they needed.

The results of our survey provided a few surprises, along with confirming a number of our impressions about our reference service:

- Our Reference Department scored very well overall on the survey, but showed a potential for scoring even higher.

- Our patrons felt that librarians were courteous and appeared knowledgeable. Interestingly enough, the busier we were, the better the patrons perceived what we were doing.

- Our patrons were very aware of the fact that we were often extremely busy at the desk since they indicated that they frequently received too little time and help.

- Librarians indicated that our patrons seemed to need a lot of extra helpmore direction and attention than other academic libraries in the program.

- Our Reference Department scored higher on being helpful to graduate students than to undergraduates.

- We spent less time answering each question than the average amount of time spent by other academic libraries.

- Our two highest user groups by a large margin were freshmen and graduate students, contrary to our impression that upper-level undergraduate students were our biggest users.

In addition to providing valuable insights into our reference service, the sur- vey results confirmed what we already knew-because our desk was so busy, we were unable to give patrons as much assistance as they felt they needed. In fact, according to Bunge and Murfin, "the librarian's report of being busy is the single largest factor associated with failure" in eliciting patron satisfaction with service. ${ }^{18}$ Obviously, this emerged as a critical area for improvement in our reference service.

\section{Reference Automation Quality Circle}

What We Did: A fourth approach to improving reference service was to find out what the reference librarians' needs were-What would empower us and enable us to do our job better? During the spring semester of 1992 the Reference Area of the library was experiencing severe growing pains. Technology was being added at an alarming rate. Reference librarians frequently did not have time to learn to use the new computerized resources before these products were made available to patrons.

One reference librarian suggested that we try a Quality Circle approach to addressing problems resulting from our perceived "technology overload." The idea of Quality Circles is based on the teachings of W. Edwards Deming and J. M. Juran. A Quality Circle is "a small group of employees and their supervisor from the same work area, who voluntarily meet on a regular basis to study quality control and productivity improvement techniques, to apply these techniques to identify and solve work-related problems, to present their solutions to management for approval, and to monitor the implementation of these solutions to ensure that they work." ${ }^{19}$ Basically, "Quality Circles teach people to break a problem or process down into small components. Difficulties that may have developed can then be recognized, and a solution (or solutions) can be developed." ${ }^{20}$ The head of reference appointed four librarians to a "Reference Automation Quality Circle," whose purpose was to anticipate and plan for the effects of new or revised automation procedures and equipment. Some of the ideas and solutions 
the committee developed for dealing with our technology expansion included:

- A daily checklist for the Reference Deskindicating which databases would be "down for repairs," changes in menus, software, location, etc. Often, the Reference Desk was not alerted to changes and fine tuning made on computers in the Reference Area.

- A "Reference Librarian Survey" requesting suggestions and comments about Reference Area issues from the librarians working at the desk.

- A "working paper" stressing the need for the removal of some clerical tasks being performed at the Reference Desk to allow librarians more time to answer patrons' reference questions. (Reference librarians serviced all computers and printers in the Reference Area, rebooted systems that were not operating correctly, and served as the central telephone switchboard for the entire library.)

What We Learned: When organizing our Quality Circle, we were not aware of one of the critical elements that makes one work-a circle is composed of a small group of employees and their supervisor. Our supervisor was not a member of the Quality Circle and the ideas and suggestions we came up with for improvement were not necessarily priorities for the department head. Eventually, the Quality Circle was abandoned, but not before at least one significant improvement was made. The head of reference was able to assign two student assistants to manage a "Computer Assistance" desk during some daytime hours, and also late hours after the reference librarians had left the desk. These students now help patrons with paper jams and disabled computers, and also with directional questions when possible. This has worked out extremely well for both the patrons and the reference librarians.

\section{CONCLUSION}

Reference librarians of the 1990 s can profit from implementation of some of the quality improvement techniques that have been used so successfully by business organizations. We were able to adapt some of these methodologies for use at the Wichita State University Library. Many elements of the projects we undertook came directly from the writings of Deming, Juran, Crosby and others in the field. These elements included: identifying the characteristics of our customers and their needs; periodically evaluating our service and identifying limitations; and promoting pride and teamwork through employee involvement in the improvement process.

We have also addressed what is perhaps the most important part of any quality improvement activity-making improvement a continuous process. After the projects described in this paper were completed, the library administration made a commitment to more than double the number of student assistant hours available at the "Computer Assistance" desk. This will allow reference librarians to concentrate on providing patrons with the additional time and attention we now know they need. To see if this change produces the desired effect, the Wisconsin-Ohio Reference Evaluation Program will be administered again within the year. And, in order to more fully address the needs of lower-level undergraduate students - one of our largest user groups according to our survey-a new "Undergraduate Services Librarian" position has been established.

We have also addressed what is perhaps the most important part of any quality improvement activitymaking improvement a continuous process.

The Reference Department continues to seek new ways to reach and teach users. The Suggestion Box is still monitored daily. And for the past two semesters, reference librarians have offered one-hour workshops on using the many CD-ROM resources available in the library. These workshops were offered at a variety of times each semester, and, while not attended by large groups of 
students, have been popular with both librarians and students. Finally, in an effort to keep our dialogue on reference service flowing, the Reference Department will soon be having its first "Rethinking Reference Retreat." This half-day meeting will allow us to discuss our reference service in depth, and to build on our improved understanding of our patrons' needs in order to develop a model for delivering to them the most appropriate high-quality reference services.

\section{REFERENCES}

1. Standards and Guidelines Committee, Reference and Adult Services Division, American Library Association, "Information Services for Information Consumers: Guidelines for Providers," RQ 30 (Winter 1990): 262-65.

2. James Shedlock, "Defining the Quality of Medical Reference Service," Medical Reference Services Quarterly 7 (1988): 49-53.

3. Michael Barrier, "Small Firms Put Quality First," Nation's Business 80 (May 1992): 22.

4. W. Edwards Deming, Out of the Crisis (Cambridge, Mass.: Massachusetts Institute of Technology, Center for Advanced Engineering Study, 1986), 23-24.

5. Terry Mackey and Kitty Mackey, "Think Quality! The Deming Approach Does Work in Libraries," Library Journal 117 (May 15, 1992): 57-61.

6. Joseph M. Juran, ed., Juran's Quality Control Handbook, 4th ed. (New York: McGraw-Hill, 1988), 2.6.

7. Charles D. Zimmerman III and John W. Enell, "Service Industries," in Juran's Quality Control Handbook, 33.1-72.

8. Ted A. Lowe and Joseph M. Mazzeo, "Crosby-Deming-Juran: Three Preachers, One Religion," Quality 25 (Sept. 1986): 22-25.

9. Richard Normann, Service Management: Strategy and Leadership in Service Businesses (New York: Wiley, 1984), 56.

10. Ibid., 9.

11. Karl Albrecht and Lawrence J. Bradford, The Service Advantage: How to Identify and Fulfill Customer Needs (Homewood, Ill.: Dow Jones-Irwin, 1990), 30.

12. Paula T. Kaufman, "Serving the University Family: Truths among the Myths," in Commitment to Service: The Library's Mission, ed. Alphonse F. Trezza (Boston: G.K. Hall, 1990), 99.

13. William H. Davidow, Total Customer Service: The Ultimate Weapon (New York: Harper, 1989), 133.

14. Marjorie E. Murfin and Gary Gugelchuk, "Development and Testing of a Reference Transaction Assessment Instrument," College \& Research Libraries 48 (July 1987): 321-22.

15. Charles A. Bunge, "Factors Related to Reference Question Answering Success: The Development of a Data-Gathering Form," RQ 24 (Summer 1985): 482-86.

16. Murfin and Gugelchuk, "Development and Testing," 314-38.

17. Charles A. Bunge, "Gathering and Using Patron and Librarian Perceptions of Question-Answering Success," in Evaluation of Public Services and Public Services Personnel, ed. Bryce Allen (Champaign, Ill.: Univ. of Illinois, Graduate School of Library and Information Science, 1991), 65.

18. Charles A. Bunge and Marjorie E. Murfin, "Reference Questions-Data from the Field," $R Q$ 27 (Fall 1987): 17.

19. Philip C. Thompson, Quality Circles: How to Make Them Work in America (New York: AMACOM, 1982), 3.

20. Robert I. Patchin, The Management and Maintenance of, Quality Circles (Homewood, Ill.: Dow Jones-Irwin, 1983), 15. 


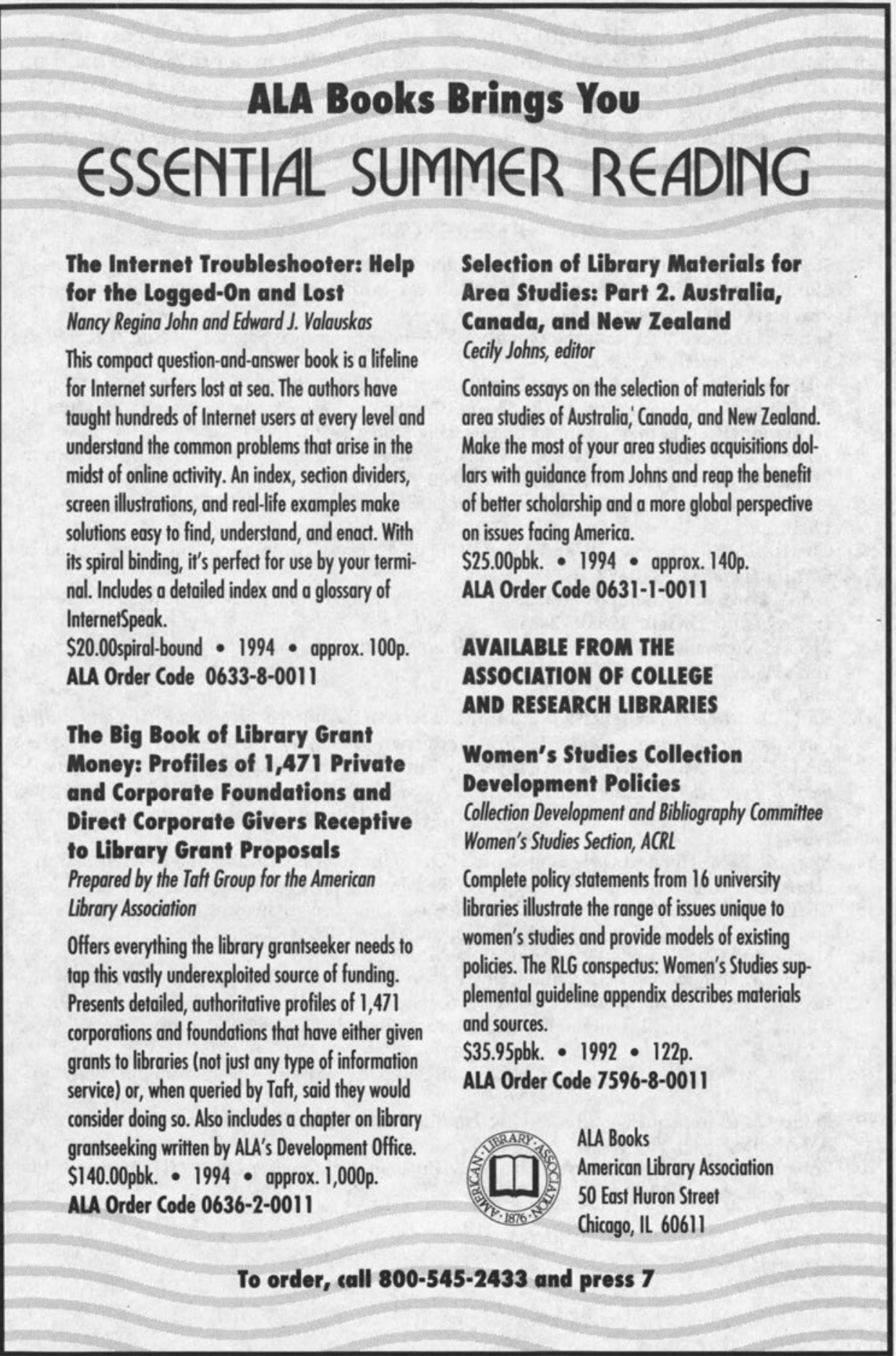

